\title{
Adsorption Kinetics of Asphaltenes at the Heptol-Water Interface
}

\author{
Mohammadjavad Mohammadi, Mohsen Zirrahi, Hassan Hassanzadeh ${ }^{1}$ \\ Department of Chemical \& Petroleum Engineering, Schulich School of Engineering, University \\ of Calgary, Calgary, Alberta T2N 1N4, Canada
}

\section{Measurements of density}

The density of all samples was measured at a temperature of $20{ }^{\circ} \mathrm{C}$ using an Anton Paar DMA 5000 density meter and repeated twice for every sample. The results are reported in Table S1. The density of n-heptane was measured to be $684 \mathrm{~kg} / \mathrm{m}^{3}$ at a temperature of $20^{\circ} \mathrm{C}$.

Table S1. Density of heptols at different asphaltene concentrations

\begin{tabular}{ccccc}
\hline $\begin{array}{c}\text { wt\% of } \\
\text { Asphaltene }\end{array}$ & $\begin{array}{c}\text { Toluene } \\
\left(\mathbf{k g} / \mathbf{m}^{\mathbf{3}}\right)\end{array}$ & $\begin{array}{c}\text { Heptol 25/75 } \\
\left(\mathbf{k g} / \mathbf{m}^{3}\right)\end{array}$ & $\begin{array}{c}\text { Heptol 50/50 } \\
\left(\mathbf{k g} / \mathbf{m}^{\mathbf{3}}\right)\end{array}$ & $\begin{array}{c}\text { Heptol 75/25 } \\
\left(\mathbf{k g} / \mathbf{m}^{3}\right)\end{array}$ \\
\hline 0 & $866.895 \pm 0.003$ & $817.880 \pm 0.003$ & $774.793 \pm 0.001$ & $731.397 \pm 0.006$ \\
0.001 & $866.864 \pm 0.028$ & $817.913 \pm 0.007$ & $774.793 \pm 0.002$ & $731.385 \pm 0.010$ \\
0.005 & $866.901 \pm 0.003$ & $817.986 \pm 0.01$ & $774.813 \pm 0.003$ & $731.591 \pm 0.031$ \\
0.01 & $866.910 \pm 0.005$ & $818.208 \pm 0.002$ & $774.856 \pm 0.006$ & $731.751 \pm 0.005$ \\
0.1 & $867.112 \pm 0.005$ & $818.446 \pm 0.006$ & $774.993 \pm 0.002$ & $731.975 \pm 0.024$ \\
1 & $869.259 \pm 0.001$ & $822.907 \pm 0.034$ & $776.833 \pm 0.017$ & $733.525 \pm 0.143$ \\
5 & $878.823 \pm 0.010$ & & & \\
10 & $890.569 \pm 0.149$ & & & \\
15 & $903.729 \pm 0.075$ & & & \\
20 & $914.437 \pm 0.088$ & & & \\
\hline
\end{tabular}

\section{Molecular weight measurements}

The molecular weight of asphaltenes dissolved in toluene was measured at eight concentrations $(5,10,15,20,30,40,50,60 \mathrm{~g} / \mathrm{lit})$ and temperature of $45^{\circ} \mathrm{C}$ using a Gonotec Osmomat 070 Vapor Pressure Osmometer (VPO). First, the instrument was calibrated with Sucrose octaacetate (678.6 $\mathrm{g} / \mathrm{mol})$ and then it was re-checked with octacosane $(394.76 \mathrm{~g} / \mathrm{mol})$. The molecular weight of octacosane was measured within $1 \%$ of the actual value.

VPO works based on vapor pressure changes when a solute is added to a solvent. The device contains a chamber that is saturated with pure solvent vapor and two separate thermistors are located inside the chamber. Since the compositions of droplets are different, this causes a temperature difference of liquid phases in equilibrium with the same vapor pressure. Therefore,

\footnotetext{
${ }^{1}$ Tel.: +1 403210 6645; Fax: +1 403284 4852; Electronic mail: hhassanz@ucalgary.ca
} 
the temperature difference makes resistance change in the thermistors which is related to the molecular weight of the solute. The detail of molecular weight calculation has been presented elsewhere. ${ }^{54}$

\section{Self-association model}

A self-association model reported by Agrawala and Yarranton was used to interpret the molecular weight data. The detailed description of the model and formulation can be found elsewhere. ${ }^{54,55} \mathrm{In}$ summary, according to this model, the asphaltenes are considered as free molecules in solution with some functional groups that are able to interact together and form aggregates. Further, the asphaltenes are divided into two classes of molecules: propagators and terminators. A propagator is defined as a molecule with various active sites while a terminator has just a single active site. The propagators are capable of linking with other similar molecules and promoting the additional associations, but, terminators do not have this capability and terminate the further association. ${ }^{54}$

Figure S1 shows the experimental and modeled molecular weight results for asphaltene at various concentrations. As can be seen, by increasing asphaltenes concentration molecular weight increases due to aggregation. First, the value of $(T / P)_{0}, K$ (the association constant, that represents the equilibrium between forward and reverse association), $M W_{T}$, and $M W_{P}$ as the inputs of the model are assumed. Second, the optimum $(T / P)_{0}$ is calculated with the constraint that the molecular weight at a concentration of $10 \mathrm{~g} / \mathrm{L}$ was approximately the same as the measured value. Third, if the calculated molecular weight for the rest of the concentrations is within a $10 \%$ error of the experimental molecular weight, the input values are the desired results of the self-association model, otherwise, the input values should be modified until the error in the fitting is minimized. The molecular weight of asphaltene as monomers can be obtained through the following equation:

$$
M W_{\text {mono }}=x_{T_{0}} M W_{T}+x_{P_{0}} M W_{P}
$$

where $(T / P)_{0}=x_{T_{0}} / x_{P_{0}}$ and $M W_{\text {mono }}$ was equal to $1637.7 \mathrm{~g} / \mathrm{mol}$.

Table S2. Parameters of the self-association model for asphaltene sample at $45^{\circ} \mathrm{C}$.

$\begin{array}{llllll}\text { Sample } & \mathbf{M W}(\mathbf{g} / \mathbf{m o l}) & \mathbf{M W}(\mathbf{g} / \mathbf{m o l}) & (\mathbf{T} / \mathbf{P})_{\mathbf{0}} & \mathbf{K}\left(\mathbf{m o l}^{\mathbf{- 1}}\right) & \mathbf{M W}_{\text {monomer }}(\mathbf{g} / \mathbf{m o l}) \\ \text { Asphaltene } & 900 & 1800 & 0.22 & 65000 & 1637.7\end{array}$




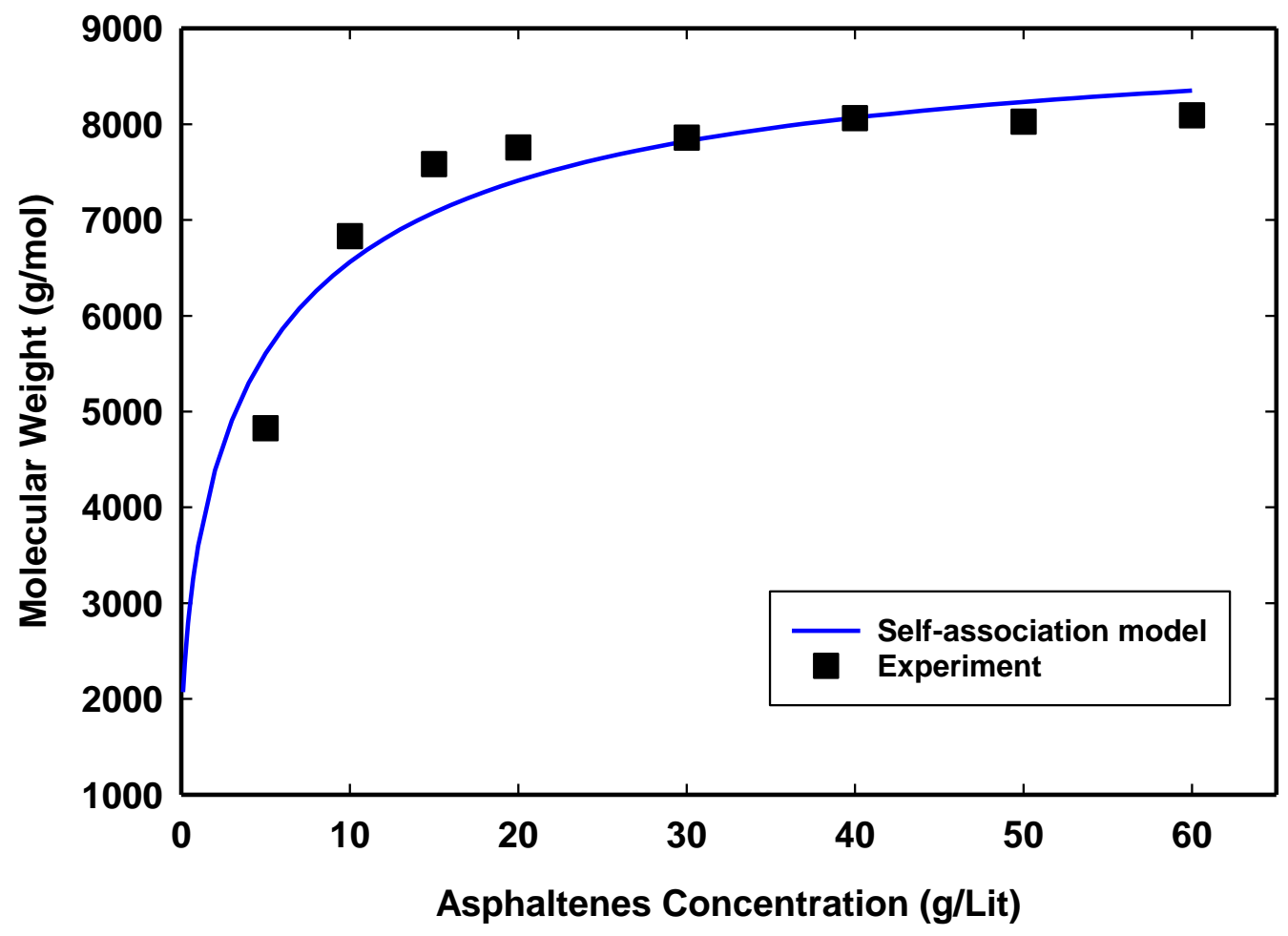

Figure S1. Fitted asphaltene molecular weight data using the self-association model. 
Dynamic interfacial tension versus $\sqrt{t}$ to obtain diffusion coefficient of asphaltenes.
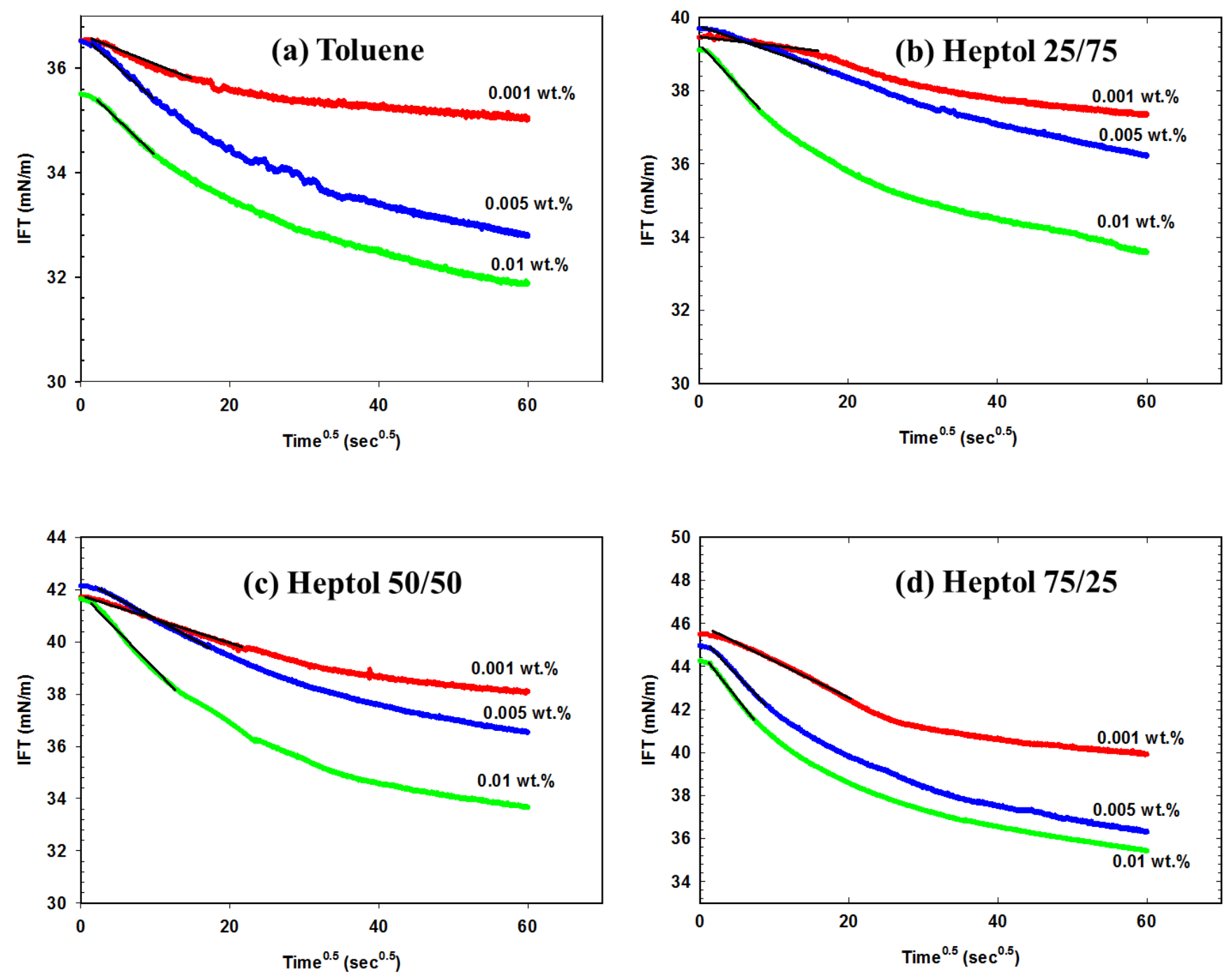

Figure S2. Dynamic interfacial tension versus $\sqrt{t}$.

Table S3. The excess surface concentration for all solvents calculated using the Langmuir isotherm (Eq. (2)).

\begin{tabular}{cccccc}
\hline $\begin{array}{c}\text { Concentration } \\
(\mathbf{w t} \%)\end{array}$ & $\begin{array}{c}\text { Concentration } \\
\left(\mathbf{m m o l} / \mathbf{m}^{\mathbf{3}}\right)\end{array}$ & $\begin{array}{c}\text { Toluene } \\
\left(\mathbf{m o l} / \mathbf{m}^{\mathbf{2}}\right)\end{array}$ & $\begin{array}{c}\text { Heptol 25/75 } \\
\left(\mathbf{m o l} / \mathbf{m}^{2}\right)\end{array}$ & $\begin{array}{c}\text { Heptol 50/50 } \\
\left(\mathbf{m o l} / \mathbf{m}^{2}\right)\end{array}$ & $\begin{array}{c}\text { Heptol 75/25 } \\
\left(\mathbf{m o l} / \mathbf{m}^{2}\right)\end{array}$ \\
\hline 0.001 & 6.11 & $3.48 \times 10^{-7}$ & $4.51 \times 10^{-7}$ & $6.47 \times 10^{-7}$ & $9.11 \times 10^{-7}$ \\
0.005 & 30.54 & $5.85 \times 10^{-7}$ & $7.68 \times 10^{-7}$ & $9.04 \times 10^{-7}$ & $1.05 \times 10^{-6}$ \\
0.01 & 61.08 & $6.39 \times 10^{-7}$ & $8.41 \times 10^{-7}$ & $9.52 \times 10^{-7}$ & $1.08 \times 10^{-6}$ \\
0.1 & 610.8 & $6.97 \times 10^{-7}$ & $9.21 \times 10^{-7}$ & $9.99 \times 10^{-7}$ & $1.096 \times 10^{-6}$ \\
1 & 6108.12 & $7.05 \times 10^{-7}$ & $9.31 \times 10^{-7}$ & $1.004 \times 10^{-6}$ & $1.098 \times 10^{-6}$
\end{tabular}

